RESEÑA HISTORICA

\title{
Cien años del colorante de Giemsa
}

\author{
José Perea-Sasiaín \\ Laboratorio de Microscopía, Sección de Biología Celular, Departamento de Morfología, \\ Facultad de Medicina, Universidad Nacional de Colombia, Bogotá, D.C., Colombia.
}

\begin{abstract}
Esta es una revisión general de los trabajos previos y subsecuentes al hallazgo del colorante de Giemsa, con énfasis en los azules de metileno policromos. Se presenta un breve bosquejo biográfico de Berthold Gustav Carl Giemsa, así como de la constitución y mecanismo de acción de su colorante y el resultado de análisis únicos por HPLC de su azur II (azul de metileno, 63,6\%; azur B, 28,6\%; azur A 4, 4\%; azur C, 1,4\%, y tionina, 1,9\%). Por tanto, el azur I no era 'puro' sino una mezcla de tionina y todos sus derivados metilados en los grupos amina 3 y 7 , muy probablemente preparada por oxidación del azul de metileno en medio ácido como lo definió Lillie. Se tabulan los usos del colorante de Giemsa informados durante los últimos 32 años.
\end{abstract}

Palabras clave: Giemsa, azur, azul de metileno, azul policromo.

Giemsa stain: one hundred years of discovery

Research work associated with the development of Giemsa stain is revied, with emphasis on the methylene blue polychromes. A short biographical sketch of Dr. Berthold Gustav Carl Giemsa is presented, alonf with the composition of his original formulation and its mec. HPLC analyses of his azur II indicated the following composition: methylene blue $63.6 \%$, azur B $28.6 \%$, azur A 4.4\%, azur C $1.4 \%$, thionin $1.9 \%$. Azur I was not "pure", but rather a mixture of thionin and all of its 3 and $7 \mathrm{~N}$ methylated derivatives. Lillie inferred that it was probably prepared by an acid oxidation process. Applications of Giemsa stain reported in the last 32 years are tabulated.

Key words: Giemsa, azure, methylene blue, polychrome methylene blue.

\section{Antecedentes históricos}

En 1880, Laveran comunicó (1) sus observaciones sobre lo que se llamó hematozoario y lo postuló como agente causal de la malaria (paludismo): el mérito extraordinario de ellas radica en el hecho de que los microscopios de luz en su época todavía no tenían totalmente perfeccionada la óptica de alta resolución y el condensador de luz de Abbe (que hubiera facilitado la observación sin teñir los parásitos) no se había aún generalizado. Igualmente, Laveran tuvo que vencer la aseveración, generalmente admitida en ese momento, de ser una bacteria el agente causal de la malaria.

La tinción diferencial de la cromatina y el citoplasma de los plasmodios mediante el uso de

Correspondencia:

Transversal 31 No. 101-18, Bogotá, D.C., Colombia. josepesa@bacata.usc.unal.edu.co

Recibido: 05/09/02; aceptado: 14/02/03 soluciones de eosina amarillenta y de azul de metileno (figura 1, I), esta última envejecida, según la leyenda, con una película superficial de moho, fue publicada por Romanowsky en 1891 (2) y resolvió toda duda que pudiera quedar sobre el papel de los plasmodios como causa directa de la malaria.

La siguiente década se caracterizó en este campo por la búsqueda de mezclas colorantes que aseguraran la tinción sistemática de dicha cromatina. Este período ha sido muy bien relatado por Woronzoff-Dashkoff (2), como se resume en el cuadro 1, con otras referencias a trabajos sobre esos colorantes (3-23).

\section{Policromos del azul de metileno}

Policromo significa de muchos colores y, en este caso, se refiere a la capacidad de teñir así que tiene un colorante. Las soluciones de azul de metileno se oxidan lentamente y eso explica el hallazgo de Romanowsky, pero no si el moho 
Cuadro 1. Antecedentes históricos hasta el colorante de Giemsa.

\begin{tabular}{|c|c|c|c|}
\hline Año & Autor & Trabajo reportado & Referencia \\
\hline 1871 & Caro* & Síntesis de la eosina amarillenta (figura1a) & 3 (p. 4426) \\
\hline 1876 & Caro* & Síntesis del azul de metileno (figura 1b) & 3 (р. 4470) \\
\hline 1882 & Koch* & Tinción Mycobacterium tuberculosis con azul policromo & 4 \\
\hline 1884 & Loeffler* & Tinción Corynebacterium diphteriae con azul policromo & 5 \\
\hline 1885 & Sahlí* & Azul policromo por tetraborato de sodio (bórax) & 6 \\
\hline 1885 & Bernthsen* & Síntesis industrial mejorada del azul de metileno & 7 \\
\hline 1885 & Bernthsen* & Preparación del azur de metileno por oxidación del azul & 7 \\
\hline 1885 & Simon* & Propone la formación del azur por desmetilación & 3 (р. 4470) \\
\hline 1888 & Chenzinsky & Tinción del Plasmodium en azul con AM y EA & 2 \\
\hline 1890 & Plehn & Tinción del Plasmodium en azul con AM impuro y EA & 2 \\
\hline 1885 & Unna* & Azul policromo por acción de carbonatos alcalinos & 8 \\
\hline 1891 & Malachowski & Tinción roja cromatina plasmodial con EA-AM y bórax & 2 \\
\hline 1891 & Romanowsky & Tinción roja de la cromatina del plasmodio con EA-AM & 2 \\
\hline 1895 & Bremer* & Precipitación del eosinato de azul de metileno & 9 \\
\hline 1899 & Nocht & Separación del azur ('rojo') del azul policromo & 2 \\
\hline 1899 & Jenner & Preparación eosinato de azul de metileno & 10 \\
\hline 1899 & Laveran-Borrel $^{*}$ & Tinción con azul policromo por óxido de plata & 11 \\
\hline 1901 & Leishman & Preparación eosinato de azul policromo & 12 \\
\hline 1901 & Reuter & Preparación eosinato de su azul policromo & 13 \\
\hline 1901 & Lazear* & Tinción del plasmodio con eosina y azul policromo & 14 \\
\hline 1902 & May y Grunwald & Tinción de sangre con eosinato de azul de metileno & 15 \\
\hline 1902 & Wright & Tinción de sangre con eosinato de su azul policromo & 16 \\
\hline 1902 & Giemsa & Preparación de azures I* y II y su mezcla con eosina** & ${ }^{*} 17,{ }^{* *} 18$ \\
\hline 1904 & Giemsa & Puesta en punto del colorante de Giemsa & 19 \\
\hline
\end{tabular}

* Caro sintetizó tanto la eosina amarillenta (EA) como el azul de metileno (AM), pero debe tenerse en cuenta que en 1885 , Bernthsen realizó una nueva y excelente síntesis industrial del azul de metileno cuyo uso aún se mantiene. Esta síntesis tiene una fase final de oxidación con bicromato de potasio, por lo cual se produce algo de azur B (8 muestras tuvieron un promedio de $4,1 \%$ con mínimo de 3,0\% y máximo de 5,1\%) (20), que acompaña al azul de metileno del comercio, así se trate del más 'puro' y los intentos para purificarlo determinan casi siempre un incremento en su contenido de azur (21). Su purificación (22) por extracción es laboriosa y no se justifica salvo para estudios o usos que ameriten su homogeneidad, en particular los que se hacen con seres humanos vivos. Ehrlich, citado en primer lugar por Woronzoff-Dashkoff (2), realizó los primeros trabajos biológicos con azul de metileno (23), como lo reconoce elegantemente Bernthsen.

aceleró el proceso. La oxidación del azul de metileno se realiza sobre los grupos metilos eliminándolos sucesivamente y se llega a producir todos los derivados metilados en los grupos amino primarios de la tionina, incluso ésta (figura $1, \mathrm{VI}$ ). El factor que no fue seriamente considerado por casi ningún autor, aparte de Kehrmann, es el hecho de que los compuestos demetilados siguen siendo oxidados y, por tanto, es imposible obtener un producto intermediario de dicha cadena sin que existan sus antecesores y los subsecuentes (24). Bernhard Nocht separó el colorante que tiñe, en asocio con la eosina, la cromatina del plasmodio y lo llamó "rojo del azul de metileno". Posteriormente, su colaborador principal en el área química, Giemsa, mostró que ese colorante es el que Bernthsen había llamado azur y había considerado, equivocadamente, que era la sulfona del azul de metileno.

Kehrmann demostró (24) que el azur es la mezcla de, por lo menos, dos derivados demetilados del azul de metileno: el azur B (figura 1, II) o trimetiltionina y el azur A (figura 1, IV) o dimetiltionina asimétrica.

\section{Métodos para obtener azul policromo}

Como señaló Lillie en sus publicaciones fundamentales $(25,26)$, los métodos de oxidación usados se pueden dividir en dos grupos: ácidos y básicos (figura 1). Los primeros métodos para realizar una oxidación progresiva de la solución del azul de metileno mediante el uso de bases se utilizaron en bacteriología: Koch y Loeffler demostraron los bacilos $(4,5)$ que recibieron, en 
justo homenaje, los nombres del primero y el de Klebs-Loeffler, con el azul policromo que aún se conoce como azul de metileno alcalino de Loeffler (27). Es lógico que el mismo procedimiento general $(6,8)$ se usara con el fin de lograr la coloración roja de la cromatina de los plasmodios como debió hacer Malachowski (2) con el azul policromo por acción del bórax (6).

\section{Oxidación en medio ácido}

La oxidación en medio ácido se realizó con bicromato de potasio o de sodio con adición de ácido clorhídrico a la solución diluida y en condiciones controladas (28). Lillie estudió en forma muy completa este tipo de oxidación (25), cambiando condiciones de concentración, temperatura y tiempo, y logró un colorante de resultados idénticos al de Giemsa (29). Poco después, Singh y Bhattacharji lograron el mismo resultado en India (30) donde estudios recientes equiparan totalmente sus resultados a los del colorante de Giemsa (31). En 1979, Russo y Lillie demostraron (32) que la relación AzB/AM puede variar entre 17,5 y $34,1 \%$ para lograr la coloración roja típica de la cromatina plasmodial: la relación óptima es $25,3 \%$, en comparación con el resultado obtenido en 1942 con concentraciones del $42 \%$. Lillie ya había recomendado proporciones y condiciones de coloración ligeramente diferentes para extendidos de sangre con el fin de estudiar su citología o para teñir los plasmodios (33). Los resultados obtenidos por Marshall mediante el análisis con cromatografía de capa fina de alta resolución (34) de colorantes obtenidos en el comercio (35), así como de muchos que preparó siguiendo el método propuesto por diversos autores (36), muestran que por oxidación en ácido se produce más dimetiltionina simétrica que azur A (figura 1, III y IV) y azur C (figura 1, V), pero en ningún caso tabula derivados de la tionolina (figura1, IX) $(35,36)$. Por su controversia con Marino en 1905 (37), en la que Giemsa se manifiesta abiertamente en contra de la preparación del azul policromo con bases, me inclino a pensar que utilizó un método de oxidación ácida, siguiendo probablemente el proceso de Simon. Otros autores modificaron los métodos anteriores (38-40). La oxidación mediante el bicromato de potasio sin adición de ácido dio buenos resultados (41), pero hay que tener en cuenta que el $\mathrm{pH}$ de esta solución es inferior a 5 (42). El Colour Index da también como método preparativo para el azur B esta oxidación (3).

\section{Oxidación en medio alcalino}

La oxidación en medio alcalino es la que da mayor variedad de tonalidades y fue ésta la razón del calificativo policromo. Es la más compleja (figura1) y sus resultados los mas difíciles de controlar como lo demostró Lillie (26). El ión hidroxilo ataca los grupos metilos sucesivamente, formando primero azur $B$ y enseguida más azur $A$ que dimetiltionina simétrica (35). Simultáneamente, se elimina uno de los grupos dimetilamino del azul de metileno dando lugar al violeta de metileno de Bernthsen o dimetiltionolina (figura1, VII), metiltionolina (figura1, VIII) y tionolina (figura 1, IX). Cuando la oxidación es extrema se puede producir incluso tionol (figura 1, X) (43). Desde un comienzo, el papel del violeta de metileno fue muy controvertido: Giemsa le negó importancia, pero añadió carbonato de potasio en la coloración para el Treponema pallidum Schaudinn propuesta por él (44) después de la controversia con Marino $(37,45)$, quien le había recomendado ensayarlo (46). Un año después, en 1906, MacNeal (47) demostró la importancia del violeta de metileno en coloraciones como la suya para el Treponema pallidum Schaudinn. Las primeras bases usadas fueron la potasa y soda cáusticas que a altas concentraciones, cuyo $\mathrm{pH}$ es de 14 , descomponen rápidamente el azul de metileno; el uso de soluciones con menores concentraciones, cuyo $\mathrm{pH}$ baja a 12 para soluciones $0,01 \mathrm{~N}$ (42), dio resultados más satisfactorios y así se usó el hidróxido de potasio (4,5,48-50), de sodio (51-56) y de amonio (57-60). Los carbonatos de los elementos del grupo II, cuyas soluciones llegan a tener un $\mathrm{pH}$ de 11,6 (42), se han empleado ampliamente, en particular el de sodio, directamente (27,61-68) o mediante el azul policromo de Unna (8,69-71), el de potasio $(27,72-$ 74) e incluso el de litio (75). Merece mención especial el bicarbonato de sodio utilizado por Reuter (13), Wright (16), Wilson (76) y Mc Clung (77) cuya solución tiene un $\mathrm{pH}$ de 8,5 , pero al calentarla el bicarbonato se transforma en carbonato y el pH de la solución sube; los análisis 
<smiles>CC(C)c1ccc2cc3ccc(C(C)C)cc3cc2c1</smiles><smiles>[R]c1ccc(C(C)C)cc1-c1ccc(I)cc1</smiles><smiles>C=c1ccc(=Cc2ccc(C(C)C)cc2C)c(C)c1</smiles><smiles>[R]CCCC(C)c1ccc2cc(C(C)C)ccc2c1</smiles>

$\begin{array}{llllll}M & \text { I I I A }\end{array}$<smiles></smiles><smiles>CC(I)c1ccc2cc3ccc(I)cc3cc2c1</smiles><smiles>C=c1ccc(=Cc2ccc(I)cc2C)c(C)c1</smiles>

I I A I<smiles>Ic1ccc2cc3ccc(C(I)I)cc3cc2c1</smiles><smiles>C=c1ccc2c(c1)Cc1cc(C)ccc1C=2</smiles>

Figura 1. Oxidación del azul de metileno en medios ácido y alcalino.

informados para el colorante de Wright (36) dan menor cantidad de productos demetilados y un contenido de azur $B$ y violeta de metileno junto al azul de metileno sin transformar con una relación de azur B/AM de 33,3 y $42,4 \%$, en dos muestras diferentes (20); otros productos de descom- posición se encuentran en cantidades menores. El tetraborato de sodio (bórax), cuyas soluciones tienen un $\mathrm{pH} 9,5$, que disminuye al calentar (42), informado por Sahli (6), Manson (27) y otros autores (78-83), da un azul policromo de excelente composición para la coloración de plasmodios, 
como lo demostraron Donaldson y Lillie (84). Un resultado igualmente bueno obtuvo Fields (85) con el azul policromo preparado por Hitch mediante el fosfato disódico. Los métodos de oxidación extrema con adición de bases fuertes como es el peróxido de sodio (86) y el del clorato de potasio en medio alcalino (87) determinan una desviación a la derecha de la secuencia oxidativa y desaparición total del azul de metileno y acúmulo de tionolinas y tionol (figura 1, derecha) (36). El óxido de plata, a pesar de su bajísima solubilidad en el agua, sube significativamente el $\mathrm{pH}$ de la solución y se comporta como una base fuerte, pero si se siguen las instrucciones de Laveran (10) y las de otros (88-92), el azul policromo resultante (azul de Borrel) debe asimilarse al de Balch (cuadro 2). En condiciones de reacción más enérgicas, Bernthsen produjo principalmente violeta de metileno con el óxido de plata (7). También se ensayaron el óxido mercúrico amarillo (93) y la alúmina activada (21).

Durante la primera guerra mundial, la necesidad llevó a Stévenel, en Guayana Francesa, a usar como oxidante el permanganato de potasio (94); los autores que lo utilizaron posteriormente lo consideran excelente (95-102), pero no se han publicado análisis posteriores de los productos de oxidación. La acción del ozono (103) no puede considerarse por sí sola, pues el autor utilizó una solución básica. Igual comentario merece el método con sulfato de cobre amoniacal (104), pero la acción del colargol preparado según Crédé (105) es más difícil de explicar. Métodos físicos como los rayos $X(21)$ y la luz ultravioleta (106) son de interés teórico pero de aplicación práctica difícil.

\section{Reseña biográfica de Giemsa}

Berthold Gustav Carl Giemsa (figura 2) nació en Blechhammer, Alemania, el 20 de noviembre de 1867 y murió en Biberwier, Austria, el 10 de junio de 1948 (107). Fue un farmacéutico con estudios de postgrado en química, mineralogía y bacteriología. Tenía conocimiento de primera mano sobre enfermedades tropicales por haber permanecido en África oriental durante 3 años como boticario y químico oficial. Al regresar a Alemania complementó sus estudios en química orgánica y bioquímica en Berlín y entró a trabajar en el Institut für Schiffs und Tropenkrankheiten (Instituto para Enfermedades de la Marinería y Tropicales) de Hamburgo, dirigido por Bernhard Nocht. Giemsa preparó azur I,muy probablemente por el método de Simon, y desarrolló un colorante para los plasmodios en gota gruesa que constituye hasta el día de hoy el patrón comparativo para cualquier otro método de diagnóstico de la malaria $(29,31,108)$. También realizó trabajos en quimioterapia con arsenicales para la sífilis, con derivados de la quinina y para la utilización del bismuto en terapéutica, pero su nombre se ha inmortalizado por el desarrollo de su colorante (14). El cuadro 3 detalla las publicaciones que hizo sobre este tema (109-121).En vida, Giemsa mereció opiniones críticas (122) sobre la forma en que publicó su trabajo, sin indicar cómo preparó el azur I, pero a su muerte, su discípulo Kirchmair

Cuadro 2. Análisis originales de azures II comerciales y azul de Balch.

\begin{tabular}{lcccccc}
\hline Colorante & $\begin{array}{c}\text { Contenido de } \\
\text { colorante (\%) }\end{array}$ & $\begin{array}{c}\text { Azul de } \\
\text { metileno (\%) }\end{array}$ & $\begin{array}{c}\text { Azur B } \\
(\%)\end{array}$ & $\begin{array}{c}\text { Azur A } \\
(\%)\end{array}$ & $\begin{array}{c}\text { Azur C } \\
(\%)\end{array}$ & $\begin{array}{c}\text { Tionina } \\
(\%)\end{array}$ \\
\hline Azur II Hollborn & 45,8 & 63,8 & 30,5 & 4,22 & 0,74 & 0,74 \\
Azur II Grubler & 69,1 & 63,5 & 26 & 4,6 & 2,0 & 3,1 \\
Giemsa (Allied) & & 64,3 & 20,2 & 11,4 & 2,2 & 0,7 \\
Giemsa (Fisher) & & 65,8 & 21 & 10,1 & 2,2 & 1,0 \\
Azul policromo (Balch) & 47,7 & 48,9 & 33,4 & 6,5 & 4,1 & 7,2 \\
\hline
\end{tabular}

Nota: el porcentaje relativo de azur B en el azur I era, por lo tanto, del $61 \%$ y $53,4 \%$, quedando $31,9 \%$ y $31,75 \%$ de azul de metileno y resultando un $8,4 \%$ y un $9,2 \%$ de azur $A$, del que no se supo, por carecer de patrón adecuado, qué porcentaje de dimetiltionina simétrica contenía. La relación AzB/AM en estas muestras es de $29 \%$ y $32 \%$. El bajo contenido de materia colorante de los azures II originales reduce la concentración real en la solución madre del colorante de Giemsa, 54\% la muestra de Hollborn y $31 \%$ la muestra de Grubler. El azul de Balch fue obtenido de Harleco, Filadelfia, EE.UU. 


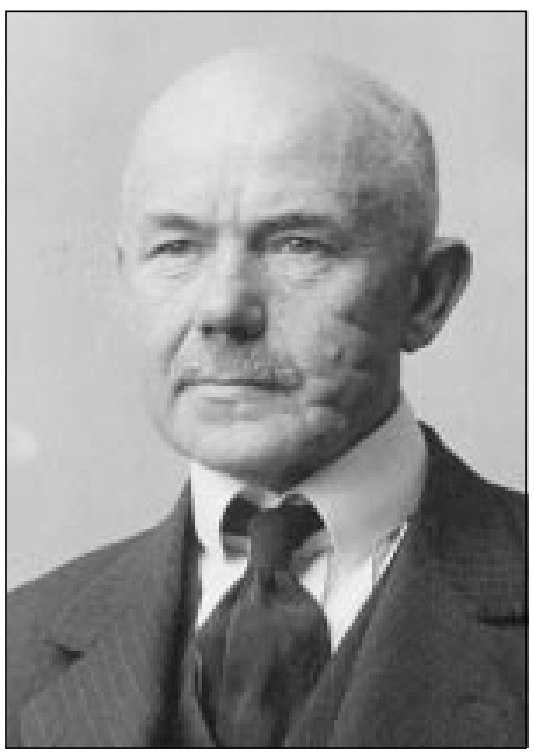

Figura 2. Retrato de Berthold Gustav Carl Giemsa, obtenido del Instituto Bernhard-Nocht, Hamburgo, Alemania, y reproducido con su autorización. Cortesía de MartinaChristine Koschwitz, bibliotecóloga, Instituto Bernhard-Nocht.

publicó un extenso artículo sobre su colorante (123); en el centenario de su nacimiento se le dedicaron al menos seis notas necrológicas en la prensa científica: cuatro referenciadas por Nauck (107) y dos más recuperadas en Medline $(124,125)$; en 1996 aparece otra biografía (126) que se une a la de Nauck en la enciclopedia biográfica de científicos alemanes (107). Su trabajo se considera uno de los cinco más importantes del Instituto Bernhard Nocht entre 1900 y 1960 (127).

\section{Colorante de Giemsa}

En su primera publicación, Giemsa (12) enumera los trabajos previos realizados, cita el azur I, sin dar ninguna indicación del método de preparación utilizado, lo equipara con el rojo del azul de metileno de Nocht (2) e insiste repetidamente en que es puro. En el segundo artículo, publicado poco después (13), mezcla el azur I con igual cantidad de azul de metileno para mejorar los resultados, llama a esta mezcla azur II y añade eosina amarillenta potásica en relación estoiquiométrica, calculando el peso molecular del azur I como el de la sulfona, no de la trimetiltionina, y añade nuevamente azur II. La mezcla final tiene azur II-eosina $0,6 \%$, azur II $0,16 \%$ (27), con la cual se prepara la solución madre del colorante, para una concentración final del $0,8 \%$ en otra mezcla de 1 volumen de glicerol por 3 de metanol químicamente puros. Esta solución debe conservarse totalmente protegida del aire con el fin de evitar su hidratación, pues los dos solventes son higroscópicos, pero la recomendación general es la de comprar la solución madre ya preparada. La solución colorante final se realiza añadiendo dos o tres gotas de solución madre por dos mililitros de agua destilada, ajustando el pH a 6,8 para estudios de

Cuadro 3. Temas de trabajo de Giemsa con su colorante.

\begin{tabular}{llc}
\hline Año & \multicolumn{1}{c}{ Tema de la publicación } & Referencia \\
\hline 1902 & Coloración de parásitos de la malaria & 12,13 \\
1904 & Simplificación y perfeccionamiento de su colorante & 14 \\
1905 & Controversia con Marino sobre uso de azul policromo & 26 \\
1905 & Tinción del Treponema pallidum Schaudinn & 27 \\
1907 & Tinción del Treponema pallidum Schaudinn en extendidos \\
1909 & Tinción de preparados microscópicos húmedos & 109 \\
1910 & Tinción de extendidos y cortes con colorante de Giemsa \\
1910 & Tinción de cortes con colorante de Giemsa & 110 \\
1910 & Tinción rápida con el colorante de Giemsa & 111 \\
1910 & Nueva tinción rápida con el colorante de Giemsa & 112 \\
1913 & Aceite de parafina para sellar preparados húmedos de Giemsa \\
1914 & Tinción rápida con colorante de Giemsa de extendidos secos \\
1922 & La esencia de la coloración de Giemsa & 113 \\
1924 & La práctica de la coloración de Giemsa & 114 \\
1934 & Historia, teoría y avances de la coloración de Romanowsky & 115 \\
1935 & Coloración de Romanowsky de protozoos en extendidos viejos & 116 \\
1935 & Observaciones de mérito sobre los gránulos de Schuffner & 117 \\
\hline
\end{tabular}


hematológicos, o a 7,4 para la búsqueda de plasmodios. El tiempo de coloración debe prolongarse por 20 a 30 minutos o más en los casos del Ilamado Giemsa lento; el exceso de azul se puede eliminar lavando el preparado con agua destilada. Giemsa diseñó su colorante y su método de coloración para el diagnóstico microscópico de la malaria y para hacerlo más eficaz los preparados más útiles son la gota gruesa de sangre, a la cual quita la hemoglobina de los glóbulos rojos por medio de agua ('lacado' o hemólisis). La tinción de extendidos de sangre en capa delgada requiere fijación, que generalmente se realiza con metanol, para el estudio fino y la clasificación de las especies de Plasmodium o de la citología sanguínea. Poco después de las publicaciones de Giemsa, Pappenheim propuso (128) iniciar la tinción de los extendidos de sangre con el colorante de May y Grunwald (15), que actúa como fijador por estar disuelto en metanol, y es en todo equivalente al colorante de Jenner, e inicia la coloración que posteriormente se completa y afina con el colorante de Giemsa: es el método panóptico de excelentes imágenes en el estudio de los extendidos de sangre para observación personal (129) y de aspirados de médula ósea o mielograma (130) (cuadro 2) (131).

Fue tal el éxito del colorante de Giemsa que ya en 1913 Langeron, principal tratadista francés en microscopía, optó por suprimir en la segunda edición de su Manual (132) la descripción del método de Borrel para preparar el azur oxidando azul de metileno con óxido de plata (11) y recomendar el uso del colorante de Giemsa.

Durante la primera guerra mundial (1914-1918), se demostró la dependencia en el suministro de colorantes biológicos de la industria alemana, la cual se estima que proveía el $88 \%$ de los colorantes de síntesis utilizados a nivel mundial (133). Para usos de laboratorio clínico, el colorante de Giemsa constituía prácticamente un monopolio de los fabricantes alemanes que contaban con el control de calidad de las firmas Grubler y Hollborn. Durante dicha guerra se realizaron ensayos para sustituir el Giemsa, que no se obtenía en el mercado, realizando ensayos originales como los de oxidación directa ya indicados y, al concluir la guerra, Langeron, en la tercera edición de su Manual (134), vuelve a incluir la descripción detallada de la preparación del azul de Borrel, que se debía asemejar mucho al azul de Balch preparado en los EE.UU., cuya composición aparece en el cuadro 2.

Durante los siguientes años se mantuvo el interés para buscar alternativas al colorante de Giemsa pero fue menor, pues ya se había reanudado el suministro de los colorantes alemanes. Giemsa se favoreció al no haber patentado su procedimiento, que en caso de ser una variante del método de Simon no cumplía el criterio de las patentes químicas en Alemania para reconocerle el hallazgo. La incautación de todas las patentes alemanas luego del Tratado de Versalles, legitimó la actitud de Giemsa.

Wittekind y su grupo propusieron el azur B para reemplazar al azur II de Giemsa en las coloraciones de sangre (135) sin tomar en cuenta, al igual que Marshall (136), la tinción de los plasmodios y otros hemoparásitos. Como consecuencia de esta propuesta, se formalizó una norma de la ICSH (137) recomendando el azur B y la eosina amarillenta como coloración para citología sanguínea.

\section{Mecanismo de la coloración de Giemsa}

El azur B con la eosina, unidos a nivel de la cromatina del plasmodio o de otros protozoarios, dan un color rojo al núcleo; el citoplasma toma el color del azul de metileno: es el 'efecto' Romanowsky en sentido estricto (figura 3a). En sentido ampliado, los autores contemporáneos amplían el término 'efecto' al color violeta rojizo nuclear de células sanguíneas y de médula ósea teñidas con el colorante de Giemsa (figura 3b): éste señaló (117) que su azur I se uniría a los radicales fosfato del $A D N$, entonces llamado ácido timonucleico, y que la eosina actúa como mordiente. Los factores que determinan este efecto, de acuerdo con el buen resumen de Woronzoff-Dashkoff (2), son los planteados por Wittekind y coautores, al igual que Marshall, quienes proponen que los colorantes interactúan con la cadena de ADN y entre sí. Wittekind considera que el colorante que primero se liga es el azur B. Marshall $(137)$ y otros $(138,139)$ dan 
importancia únicamente al azur B pero no proponen ninguna explicación para el color rojizo de la cromatina del plasmodio teñido con el colorante de Giemsa y los derivados del método de Romanowsky, que difiere a simple vista del violáceo purpúreo de los núcleos de ciertas células hemáticas, pues sus publicaciones no mencionan tinciones de plasmodios.

\section{Perspectiva actual}

Al contrario de los nombres de investigadores de igual o mayor mérito, como es Lillie, el de Giemsa permanece incólume en la literatura médica y científica. La búsqueda 'Giemsa' por Medline arroja un total de 3.694 publicaciones entre 1970 y el 31 de diciembre del 2002 y clasificadas después de la automatización electrónica del sistema. La ampliación de la búsqueda por ese sistema cubre los resúmenes y textos de los artículos en que se utilizó el colorante o en que se hace referencia al mismo Giemsa y sus estudios (cuadro 4).

En contraste con el buen número de trabajos con células sanguíneas, sólo 14 están clasificadas como pertinentes a «hematología» paradoja explicada por el uso de los sistemas automatizados de recuentos globulares sanguíneos y de los diferentes tipos de leucocitos (leucograma o fórmula leucocitaria) que han relegado a último término en la práctica (140) el interés investigativo sobre los colorantes de las células sanguíneas como métodos de estudio: hay amplia oferta de equipos automatizados en el comercio y la indicación de los fabricantes es usar sólo los colorantes que ellos proveen y para los cuales han calibrado sus equipos (141).

Cuadro 4. Usos actuales del colorante de Giemsa.

\begin{tabular}{|c|c|c|}
\hline Área de estudio & Temas específicos & Referencias en Medline 1970-2002 \\
\hline Citología & $\begin{array}{l}\text { Células madres } \\
\text { Células sanguíneas } \\
\text { Leucocitos } \\
\text { Medula ósea, células } \\
\text { Hemocitoblasto } \\
\text { Megacariocito } \\
\text { Citodiagnóstico }\end{array}$ & $\begin{array}{r}135 \\
777 \\
648 \\
17 \\
4 \\
118 \\
30 \\
373\end{array}$ \\
\hline Genética & $\begin{array}{l}\text { Cromosomas } \\
\text { Bandas cromosomas } \\
\text { id con Giemsa-11* }\end{array}$ & $\begin{array}{r}1.147 \\
39 \\
5 \\
211\end{array}$ \\
\hline Patología & $\begin{array}{l}\text { Biopsias } \\
\text { Leucemia }\end{array}$ & $\begin{array}{r}1.166 \\
256\end{array}$ \\
\hline Microbiología & $\begin{array}{l}\text { Virus } \\
\text { Chlamydia } \\
\text { Bacteria } \\
\text { Pneumocystis carinii } \\
\text { Helicobacter pylori } \\
\text { Borrelia } \\
\text { Legionella } \\
\text { Treponema sp. }\end{array}$ & $\begin{array}{r}121 \\
97 \\
676 \\
84 \\
278 \\
16 \\
4 \\
2\end{array}$ \\
\hline Parasitología & $\begin{array}{l}\text { Toxoplasma gondii } \\
\text { Leishmania sp. } \\
\text { Plasmodium sp. }\end{array}$ & $\begin{array}{r}26 \\
61 \\
134\end{array}$ \\
\hline Micología & & 529 \\
\hline
\end{tabular}

Nota: el número de referencias del área de estudio no guarda necesariamente relación con el número de referencias sobre los temas específicos dentro de cada área. 


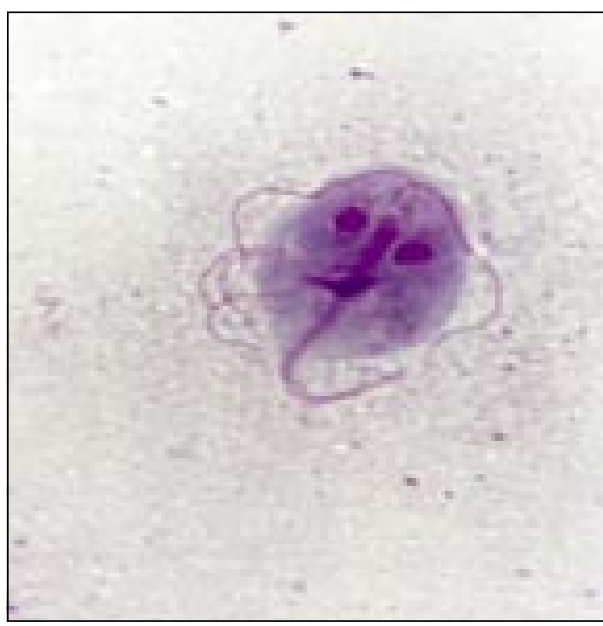

3a.

Figura 3a. Trofozoíto de Giardia duodenalis teñido con coloración de Giemsa. 1000X. Obsérvese que los núcleos toman un color rojizo, ocasionado por la unión del azur B con la eosina a nivel de la cromatina, mientras el citoplasma toma el color del azul de metileno. Este es el denominado "efecto Romanowsky" (cortesía del Laboratorio de Parasitología del Instituto Nacional de Salud). 3b. Megacariocito en extendido de médula ósea humana teñido con la coloración panóptica de Pappenheim (May-Grunwald-Giemsa). Aumento 1.000X, con ampliación fotográfica posterior. Obsérvese el color violeta rojizo de los núcleos del megacariocito y de las células que lo rodean. El color se debe a la unión del azur I con los radicales fosfato del ADN. La flecha señala un grupo de plaquetas segregadas del megacariocito (cortesía de la doctora Alicia Gaitán Cortés de Perea, Departamento de Morfología, Facultad de Medicina, Universidad Nacional de Colombia).

Tzanck (142) desarrolló un método de citodiagnóstico inmediato mediante la coloración de extendidos o impresiones por el método panóptico de Pappenheim (128) o May-GrunwaldGiemsa que se sigue utilizando (129) (figura 2). El área de la genética es la del mayor número de comunicaciones en la que se utilizó el colorante de Giemsa después de diversos tratamientos previos al material de estudio. El uso de colorantes fluorescentes permite comparar las bandas obtenidas con los dos métodos. En el llamado Giemsa-11 (143), la solución del colorante en tampón fosfato se ajusta a un pH final de 11,6 añadiendo solución de soda cáustica. Esta mezcla fue utilizada inicialmente para demostrar la heterocromatina densa del cromosoma 9 y posteriormente se ha generalizado.

Al pH utilizado se establecen condiciones similares a las que obtuvo Giemsa al añadir carbonato de potasio para la tinción de Treponema pallidum Schaudinn y se generan derivados de la tionolina, principalmente el violeta de metileno. Hay un total de 1.028 citas de Giemsa-11.
La tinción de cortes histológicos fue una de las áreas iniciales de trabajo con el azul de metileno oxidado y la eosina (144). Giemsa indicó el uso de su colorante para cortes $(111,112)$, otros autores usaron sistemáticamente el azur II en histología y embriología (145). En el momento actual, la coloración de Giemsa se utiliza para teñir biopsias del más variado origen y, entre nosotros, las de mucosa gástrica para teñir y detectar la presencia de Helicobacter pylori. El uso inicial de esta coloración como rutina no prueba la ausencia de dicha bacteria, pero sólo estos negativos ameritan el estudio con métodos más precisos pero más complejos y costosos.

El colorante de Giemsa sigue teniendo un gran uso en la búsqueda de Plasmodium en sangre: el método en gota gruesa es el patrón de comparación de los métodos de fluorescencia e inmunofluorescencia y de los múltiples colorantes comerciales (146). El método panóptico es muy conveniente para observar no sólo la citología sanguínea sino también la presencia eventual de hemoparásitos. 


\section{Comentarios}

La multiplicidad de métodos para preparar azul de metileno policromo, al igual que los numerosos métodos propuestos para reemplazar el colorante de Giemsa, muestran las dificultades para utilizarlo y sólo deberían considerarse sus equivalentes los que se hacen con azul de metileno policromo por oxidación en ácido. Los métodos que utilizan policromos preparados en medio alcalino no lo serían en sentido estricto.

Discombe propuso (147) que toda publicación que incluya coloraciones de sangre debería incluir el origen y el número de lote del colorante del fabricante; en realidad, el ideal sería incluir el análisis porcentual de las sustancias contenidas en la mezcla, pero esto no resulta práctico y menos para soluciones que cambian al actuar. Una alternativa sería la mezcla de colorantes de alta pureza disponibles en la actualidad sin un sobrecosto exagerado. Este sistema ya fue propuesto por varios autores con colorantes menos homogéneos (148-150).

\section{Agradecimientos}

Al doctor Santiago Nicholls, editor de Biomédica, quien acogió mi idea de escribir esta revisión a la cual ha aportado enmiendas fundamentales para hacerla más eficaz y modificaciones que han mejorado su presentación sustancialmente. Al doctor Gerzaín Rodríguez Toro por facilitarnos generosamente las dos muestras de azur II de Grubler y Hollborn. A la doctora WoronzoffDashkoff por recibirlas y enviarlas al laboratorio de la Food and Drug Administration en Denver, Colorado, EE.UU., y remitirnos los resultados. A los doctores José Roybal y Sherri Turnipseed por realizar los análisis del cuadro III. A la química Ingrid Herrera Garnica por el dibujo y composición de la figura $\mathrm{I}$.

\section{Bibliografía}

1. Laveran A. Note sur un nouveau parasite trouvé dans le sang de plusieurs malades atteints de fièvre palustre. CR Acad Sc 1880;92:1268.

2. Woronzoff-Dashkoff KPK. The Ehrlich-ChenzinskyPlehn-Malachowski-Romanowsky-Nocht-Jenner-MayGrunwald-Leishman-Reuter-Wright-Gíemsa-Lillie-RoeWilcox stain. Clin Lab Med 1993;13:759-71.
3. Society of Dyers and Colourists. Colour Index. Third edition. Bradford and London: Lund, Humphries; 1971. p.4470.

4. Koch R. Der Aetiologie der Tuberkulose. Berliner Klin Wochenschr 1882;19:221-30.

5. Loeffler F. Die Klebs'chen Staebchen. Mittel Kaiserl Gesundheimte 1884;421. En: Breed RS, editor. Bergey's manual of determinative bacteriology. Seventh edition. Baltimore: Williams \& Wilkins; 1957.

6. Sahli H. Ueber die Anwendung von Boraxmethylenblau fur die Untersuchung des centralen Nervensystems und fur die Nachweis von Mikroorganismen, speziell fur bakteriologischen Untersuchung der nervosen Centralorgans. Z Wiss Mikrosk 1885;2:49-51.

7. Bernthsen A. Studien in der Methylenblaugruppe. Liebigs Ann Chem 1885;230:73-211.

8. Unna PG. Uber die Reifung unserer Farbstoffen. Z Wiss Mikrosk1891;8:475-87.

9. Bremer L. Ueber das Paranuklearkoerpechen der gekernten Erythrocyten, nebst Bemerkungen ueber den Bau der Erythrocyten im Algemeinen. Arch Mikrosk Anat 1895;45:433-50.

10. Jenner $L$. A new preparation for rapidly fixing and staining blood. Lancet 1899;1:370-1.

11. Laveran A. Sur un procédé de coloration des noyaux des hématozoaires endoglobulaires des oiseaux. CR Soc Biol 1899;51:249-52.

12. Leishman WB. The application of Romanowsky stain in malaria. Brit Med J 1901;1:635-7.

13. Reuter K. Ueber den farbenden Benstandtell der Romanowsky Nochtschen Malaria plasmodienfarbung. Eine Reindarstellung und praktische Verwendung. Zentralbl Bakteriol 1. 1901;30:248-56.

14. Lazear JW. Structure of the malarial parasite. Johns Hopkins Hosp Rep 1901;10:2-9.

15. May R, Grunwald L. Ueber Blutfarbungen. Zentralbl Inn Med 1902;23:265-70.

16. Wright JH. A rapid method for the differential staining of blood films and malarial parasites. J Med Res (Boston) 1902;7:138-44.

17. Giemsa G. Farbenmethoden fur Malariaparasiten. Zentralbl Bakteriol 1. 1902;31:429-30.

18. Giemsa G. Farbenmethoden fur Malariaparasiten. Zentralbl Bakteriol 1. 1902;32:307-13.

19. Giemsa G. Eine Vereinfachung und Vervollkommung meiner Methylenazur-Methylenblau-Eosin Farbemethode zur Erzielung der Romanowsky-Nochtsen Chromatinfarbung. Zentralbl Bakteriol 1. 1904;37:308-11.

20. Lubrano GJ, Dean WW, Heinsohn HG, Stastny M. The analysis of some commercial dyes and 
Romanowsky stains by high performance liquid chromatography. Stain Technol 1977;52:13-23.

21. Stenstrom W, Street HR. Effects of X-rays on methylene blue and on thimethylthionine. Proc Soc Exp Biol Med 1935;32:1498-500.

22. Marshall PN, Lewis SM. The purification of methylene blue and azure $B$ by solvent extraction and crystallisation. Stain Technol 1975;50:375-81.

23. Ehrlich P. Uber das Methylenblau und seine klinische bakterioskopische Verwertung. Klin Med 1881;2:710-3.

24. Kehrmann F, Duttenhofer A. Ueber Methylenazur. Ber Dtsch Chem Ges 1906;39:1403-8.

25. Lillie RD. Studies on polychrome methylene blue. II. Acid methods of polychroming. Stain Technol 1942;17:97110.

26. Lillie RD. Studies on polychrome methylene blue. III.Alkali methods of polychroming. Stain Technol 1943;18:1-11.

27. Langeron M. Précis de microscopie. 7ème. ed. Masson, Paris, 1947. p. 590.

28. MacNeal WJ, Killian JA. Chemical studies on polychrome methylene blue. J Am Chem Soc 1926;48: 740-7.

29. Lillie RD. A Giemsa staining of quite constant composition and performance, made in the laboratory from eosin and methylene blue. Public Health Rep 1943;58:449-52.

30. Singh J, Bhattarchaji LM. Rapid staining of malaria parasites by a water soluble stain. Indian Med Gaz 1944; 79:102-4.

31. Gautam AS, Sharma RC, Bhatt RM, Gupta DK. JSB versus Giemsa stain: an evaluation. Indian J Malar 1992; 29:251-3.

32. Russo A, Donaldson PT, Lillie RD. Lower azure B methylene blue ratios in Giemsa type blood and malaria stains. Stain Technol 1978;53:37-41.

33. Lillie RD. A note on Giemsa stains. Am J Trop Med 1949;29:625.

34. Marshall PN, Lewis SM. A rapid thin layer chromatographic system for Romanowsky blood stains. Stain Technol 1974;49:235-40.

35. Marshall PN, Lewis SM. Batch variations in commercial dyes employed for Romanowsky-type staining: a thin layer chromatographic study. Stain Technol 1974; 49:351-8.

36. Marshall PN. Romanowsky-type stains in haematology. Histochem J 1978;10:1-29.

37. Giemsa G. Bemerkungen zur Farbung der Spirochaeta pallida (Schaudinn). Dtsch Med Wochenschr 1905;31:1026-7.

38. Manwell RD. The J.S.B. stain for blood parasites. J Lab Clin Med 1945;30:1078-82.
39. Manwell RD, Feilgelson P. A modified method of preparing the J.S.B. stain. J Lab Clin Med 1948;33:77782.

40. Bami HL, Nair CP. Composition of J.S.B. stain and factors influencing its quality. Stain Technol 1955;30:261-8.

41. Vergara F. Como logré colorar el hematazoario de Laveran valiéndome del azul de metileno ordinario. Mem Soc Cient Antonio Alzate 1919;37:397-9.

42. Budavari S, O'Neil MJ, Smith A, Heckelman PE. The Merck index. XIth edition. Rahway: Merck Co.;1979. p.113, 1213, 1359.

43. Scott RE, French RW. Standardization of biological stains II. Methylene blue. Military Surg 1924;55;337-52.

44. Giemsa G. Coloration des protozoaires. Ann Inst Pasteur 1905;19:346-50.

45. Marino F. Au sujet de la coloration des protozoaires. Réponse à 1'article ci-dessus de M. G. Gliemsa. Ann Inst Pasteur 1905;19:351-2.

46. Marino F. Coloration des protozoaires et observations sur la neutrophilie de leurs noyaux. Ann Inst Pasteur 1904;18:761-6.

47. MacNeal WJ. A rapid and simple method of staining Spirochaeta pallida. JAMA 1907;48:609-10.

48. Hanna W. A modification of the Romanowsky-Ruge method of staining the Plasmodium of malaria. Lancet 1901;1:1010.

49. Mandelbaum M. Ein vitale Farbung der Spirochaeta pallida. Munch Med Wochenschr 1907;54:2268-9.

50. Schuffner W. Eine einfache Farbung der Leukocyten in der Zahlkammer mit Differenzierung der einzenen Zellarten. Munch Med Wochenschr 1911;58:27.

51. Bruckner J. Une modification pratique du procédé de Romanowsky pour le sang et tréponème. CR Soc Biol 1908;64:968-9.

52. McJunkin FA. A polychrome stain with advantages over the Giemsa. JAMA 1915;65:2164-5.

53. Beck FA. Method of preparing the eosinate of methylene blue and method for staining. JAMA 1918;71:1651.

54. Barlow DL. A simplified method of preparing a modified Romanowsky blood stain. Med J Austral 1923;11:90.

55. Michelson L. An improved methylene blue eosinate. J Lab Clin Med 1942;27:552-3.

56. Ezzat HG. A modified procedure for the preparation of Romanowsky stain. Med Lab Sci 1987;44:86.

57. Tribondeau L, Dubreuil J. Nouveaux colorants pour microscopie dérivés du bleu de méthylène. CR Acad Sci 1917;164:551-3.

58. Grosso G. Colorazioni panoptiche e ad allettivita microchimica nell hematologia e nella tecnica istologica. Pathologica 1918;10:163-5. 
59. Fortner H. Einiges zur Farbung mit MethylenblauAmmoniakgemischen. Z Wiss Mikrosk 1927;44:165-72.

60. Mayoral P. Las tinciones pancrómicas del laboratorio de higiene de Nariño. Med Cir 1942;9:11-42.

61. Hastings TW. A method of preparing a permanent Nocht stain (Nocht-Jenner stain). J Exp Med 1905;7:265-79.

62. Billet A. Modification à la méthode de coloration de Romanowsky-Giemsa. CR Soc Biol 1906;61:753-4.

63. Cropper J. Rapid diagnosis of malaria. Brit Med J 1912; (I):891.

64. Carageorgiades H. Deux colorants neutres pour la méthode panoptique, de préparation facile et rapide. C $\mathrm{R}$ Soc Biol 1918;81:925-8.

65. Cretin A. Procédé de préparation et mode d'utillisation du polyéosinate de bleu de méthylène et de ses dérivés. Bull Mem Soc Med Hop Paris 1920;36:1320-3.

66. Puntoni V. La preparazione dell Azur di metilene ed il suo uso per la colorazioni alla Romanowsky. Ann Ig 1926;36:24-30.

67. McNamara WL. Giemsa stain for tissue. Rapid method. J Lab Clin Med 1933;18:752.

68. Jerace F. La colorazione alla Romanowsky con il liquido de Puntoni. Ann Ig 1938;48:606-7.

69. Harris HF. A modification of the Romanowsky stain. Zentralbl Bakteriol 1. 1903;34:188-91.

70. Terry BT. Increasing the pathologist's usefulness and his rewards. With directions for preparation and use of a polychrome methylene blue stain for frozen sections. JAMA 1920;74:1775-7.

71. Assmann G. Eosin-methylene blue and eosin-methylene azur for staining blood smears. Munch Med Wochenschr 1926;73:2210.

72. Urtubey A. Nota sobre un procedimiento sencillo, rápido y seguro para preparar la tintura de RomanowskyLeishman. Rev San Mil 1906;20:517-9.

73. Goodpasture EW. An acid polychrome methylene blue solution for routine and special staining. JAMA 1917; 68:998.

74. Roques H, Jude A. Nouveau procédé de préparation du polyéosinate de méthylene. Bull Soc Hist Nat Afrique du Nord 1940;31:142-6.

75. Goldhorn LB. Method for polychroming methylene blue. NY Univ Bull Med Sc 1901;1:57-69.

76. Wilson TM. On the chemistry and staining properties of certain derivatives of the methylene blue group when combined with eosin. J Exp Med 1907;9:645-70.

77. Emmel VM, Cowdry EV. Laboratory technique in biology and medicine. Baltimore: Williams \& Wilkins; 1964. p.359.

78. Russell FF. A combined staining method for malarial parasites and blood smears. JAMA 1915;64:2131-2.
79. Sénevet G. Note sur un procédé de coloration de I'hématozoaire du paludisme. Bull Soc Path Exot 1917; 10:540-2.

80. Goubault MA. Mode de préparation et mode d'éosinate de méthylene. Le «Pancolore». Rev Path Comp 1918; 18:118-9.

81. Arnaud R. Note sur une nouvelle méthode panoptique rapide de coloration du sang et des parasites dans les frottis. CR Soc Biol 1919;82:208-9.

82. Goldie H. Notes sur la coloration du sang et de hémoparasites. Bull Soc Path Exot 1933;26:461-4.

83. Joannides G. A simple method of staining malarial parasites. J Lab Clin Med 1947;32:89.

84. Donaldson PT, Russo A, Reynolds D, Lillie RD. Borax methylene blue: a spectroscopic and staining study. Stain Technol 1978;53:225-7.

85. Field JW. Further note on a method of staining malarial parasites in thick blood films. Trans Roy Soc Trop Med Hyg 1941;35:35-42.

86. Proescher F, Krueger AP. A simple and rapid method for the preparation of polychrome methylene blue and thiazine red. A rapid method for staining frozen sections with thiazine red. J Lab Clin Med 1924;10:153-9.

87. Tzung CY. Methylene violet (Bernthsen) by the zincalkali-chlorate hydrolysis of methylene blue. Stain Technol 1964; 39:351-8.

88. Gauducheau A. Mélange colorant pour remplacer le Giemsa. Bull Soc Med-Chir Indochine 1916;7:301-5.

89. Shortt HE. Note on Romanowsky staining. Indian J Med Res 1918;6:124-6.

90. Tribondeau L. Sur la recherche de l'hématozoaire de Laveran. Bull Soc Path Exot 1918;11:196-205.

91. Motais F. Nouvel éosinate de méthylène. Bull Soc Path Exot 1920;13:206-8.

92. Suldey EW. Procédé simple de préparation d'un éosinate de bleu de Borrel pour les colorations hématologiques. Bull Soc Path Exot 1920;13:205-6.

93. Bahrami A. Un colorant de remplacement du Giemsa. Bull Soc Path Exot 1947;40:110-1.

94. Stévenel L. Le bleu au permanganate de potasse. Bull Soc Path Exot 1918;11:870.

95. Zottner G. Coloration du sang et des hématozoaires par la méthode de Stévenel modifiée. CR Soc Biol 1932; 111:423-4.

96. Cerrutti C. Contríbuto allo studio dei metodo di colorazione di Stévenel modificado du Zottner. Arch Ital Sci Med Colon 1933;14:194-200.

97. Boyé R. Méthode de coloration extra-rapide des hématozoaires du paludisme par le Romanowsky simplifié au bleu de Stévenel éosine en 2 temps. Bull Soc Path Exot 1940;33:248-52. 
98. Simeons ATW. Economy and simplification in the staining of blood slides. Indian Med Gaz 1942;77:725-9.

99. Chernoff $\mathbf{A H}$. A rapid staining technique for the malarial parasites. Military Surg 1943;93:480-1.

100. Van Scyoc GP. Modified rapid staining technic for malaria. Hosp Corps Quart 1945;18:47-8.

101. Bhattarchaji LM, Singh J, Sen Gupta GP. A simple methylene blue-eosin substitute for Leishman and Giemsa stains. Indian Med Gaz 1946;81:400-1.

102. Angulo Ramos G. El colorante de Stévenel para sangre. Laboratorio 1948;6:27-31.

103. Puntoni V. La préparation de l'azur de méthylène au moyen de 1 'ozone et son emploi pour les colorations par la méthode de Romanowsky. CR Soc Biol 1926; 94:21-3.

104. Kuhn C. Un nouveau colorant. Le Sang 1933;7:75860.

105. Koreck J. Zur Farbetechnik der Malariaparasiten. Dtsch Med Wochenschr 1903;79:300-1.

106. Marie SU, Raleigh JT. The use of ultraviolet rays for the polychromatization of methylene blue. J Lab Clin Med 1924;10:250.

107. Nauck EG. Giemsa Berthold Gustav Carl, im Neue Deutsche Biographie Herausgegeben von der historische Kommission bei der Bayerischen Akademie der Wissenschaften, VI band. Ducker, Humblot, Berlin; 1964. p.371-2.

108. Pividal Grana J, Machín Sánchez R, Fachado Carvajales A. Comparación simultánea de los colorantes naranja de acridina y Giemsa en el diagnóstico del paludismo. Rev Cubana Med Trop 1986;38:289-95

109. Giemsa G. Beitrag zur Farbung der Spirochaeta pallida (Schaudinn) in Austrichpreparaten. Dtsch Med Wochenschr 1907;33:676-9.

110. Giemsa G. Ueber die Farbung von Feuchtpreparaten mit meiner Azur-Eosinmethode. Dtsch Med Wochenschr 1909;35:1751-2.

111. Giemsa G. Zur Farbung von Feuchtpreparaten und Schnitten mittels der Azureosinmethode. Zentralbl Bakteriol 1. 1910;54:489-90.

112. Giemsa G. Ueber die Farbung von Schnltten mittels Azur-Eosine. Dtsch Med Wochenschr 1910;36:552-3.

113. Giemsa G. Ueber eine neue Schnellfarbung mit meiner Azur-Eosin losung. Arch Schiff Tropenhyg 1910;14:69596.

114. Giemsa G. Ueber eine neue Schnellfarbung mit meiner Azur-Eosin losung. Munch Med Wochenschr 1910; 57:2476.

115. Giemsa G. Paraffinoel als Einschlusemittel fur Romanowsky Praparate und als Konservierung- sflussigkeit fur ungefarbte Trockenaustriche. Zentralbl Bakteriol I. 1913;70:444-6.

116. Giemsa G. Zur Schnellfarbung (RomanowskyFarbung) von trocken Austrichen. Zentralbl Bakteriol 1. 1914; 73:493-6.

117. Giemsa G. Das Wesen des Giemsa Farbung. Zentralbl Bakteriol 1. 1922-3;89: 99-106.

118. Giemsa G. Zur Praxis der Giemsa Farbung. Zentralbl Bakteriol 1. 1924;91:343-6.

119. Giemsa G. Geschichte, Theorie und Weiterentwicklung der Romanowsky Farbung. Med Welt 1934;8:1432-4.

120. Giemsa G. Die Romanowsky Farbung protozoischer Blutparasiten in alten Trockenaustrichen. Zentralbl Bakteriol 1935;134:483-6.

121. Giemsa G. Ueber eine bemeckenswerte Fehlerquelle bei der farberischen Darstellung der SchuffnerTupfelung. Munch Med Wochenschr 1935;82:1075-6.

122. Conn HJ. Biological stains, $7^{\text {th }}$ ed. Baltimore: Williams \& Wilkins; 1961.

123. Kirchmair H. Die Giemsa-Farbung (AzurMethylenblau-Eosin Farbung). Forsch u Forscher Tiroler Arztschule 1950;2:107-31.

124. Editor. Gustav Giemsa (1867-1948). Triangle 1967;8:1.

125. Vogel H. Gustav Giemsa (1867-1948). Z Tropenmed Parasitol 1967;18:386.

126. Jonecko A. Gustav Giemsa (1867-1948) his universal method of microscopic dyeing and his contribution for tropical medicine and chemotherapy. Arch Hist Filoz Med 1996;59:31-40.

127. Mannweiler E. The scientific accomplishments of coworkers in the Bernhard Nocht Institut between 1900-1960. Zentralbl Hy Unweldmed 1991;192:187206.

128. Pappenheim A. Panoptische Universalfarbung fur Blutpreparate. Med Klin 1908;4:1244.

129. Benattar L, Flandrin G. Morphometric and quality control for a May-Grunwald-Giemsa stained preparation. A 40 center cooperative study. Leuk Lymphoma 1999; 33:587-91.

130. Kass L. Interpretation of bone marrow aspirates and biopsies. En: Bick RL, editor. Hematology clinical and laboratory procedures. St Louis: Mosby; 1993.

131. Roybal JE, Munns RK, Holland DC, Hurlbut JA, Long RA. Application of electrochemical and UV/visible detection to the LC separation and determination of methylene blue and its demethylated metabolites from milk. In: Agarwal VK, editor. Analysis of antibiotic drug residues in food products of animal origin. New York: Plenum; 1992.

132. Langeron M. Précis de microscopie. 2ème ed. Paris: Masson; 1913. 
133. Delamare F, Guineau B. Los colores, historia de los pigmentos y colorantes. Barcelona: BSA; 2000.

134. Langeron M. Précis de microscopie. 3ème ed. Paris: Masson; 1921.

135. Wittekind D, Kretschmer V, Sohmer J. Azure B-eosin Y stain as the standard Romanowsky-GIEMSA stain. Brit J Haematol 1982;51:391-3.

136. Marshall PN. Methylene blue-azure B-eosin as a substitute for May-Grunwald-Giemsa and Jenner-Giemsa stains. Microscopica Acta 1977;79:153-6.

137. International Committee for Standardization in Haematology. ICSH reference method for staining of blood and bone marrow films by azure $B$ and eosin $Y$ (Romanowsky stain). Brit J Haematol 1984;57:707-10.

138. Wyandt HE, Wysham DG, Minden SK, Anderson RS, Hecht F. Mechanisms of Giemsa banding of chromosomes. 1. Giemsa-11 banding with azure and eosin. Exp Cell Res 1976;102:85-94.

139. Curtis DJ, Horobin RW. Staining banded human chromosomes with Romanowsky dyes; some practical consequences of the nature of the stain. Human Gen 1975;26:99-104.

140. Pierre RV. Peripheral blood film review. The demise of the eyecount leukocyte differential. Clin Lab Med 2002; 22:279-97.

141. Gilliland JW, Rogers CH, Sage BH. Blood stain for automatic differential analysis of leukocytes. Clin Lab Products 1974;3:2-8.
142. Tzanck A, Aron-Brunetiere R. Le cyto-diagnostic immédiat. Sem Hop 1949;3973-3980.

143. Gagne R, Laberge C. Specific cytological recognition of the heterochromatic segment of number 9 chromosome in man. Exptl Cell Res 1972;73:239-42.

144. Sternberg C. Eine Schnittfarbung nach der Romanowskyschen Methode. Zentralbl Allg Pathol 1905; 16:293-4.

145. Von Prowazek S. Zur Kenntnis der Giemsafarbung von Standpunkt der Zytologie. Z Mikrosk 1914;31:116.

146. Collier JA, Longmore JM. The reliability of the microscopic diagnosis of malaria in the field and in the laboratory. Ann Trop Med Parasitol 1983;77:113-7.

147. Discombe G. Application des méthodes cytologiques modernes aux travaux de laboratoire clinique. Rev Hematol 1950;5:565-79.

148. Hollande AC. Solution colorante à base d'éosinate d'azur et de violet de méthylène. CR Soc Biol 1916; 79:746-8.

149. MacNeal WJ. Tetrachrome blood stain: an economical and satisfactory imitation of Leishman's stain. JAMA 1922;78:1122-3.

150. Léger A. Mode de préparation simplifiée d'un éosinate de méthylène. Bull Soc Path Exot 1925;18:464-5. 


\title{
Fe de erratas
}

Biomédica

2003;23:5-18

\section{Cien años del colorante de Giemsa}

\author{
José Perea-Sasiaín
}

Laboratorio de Microscopía, Sección de Biología Celular, Departamento de Morfología, Facultad de Medicina, Universidad Nacional de Colombia, Bogotá, D.C., Colombia

This is a general review of work previous and subsequent to Giemsa stain, emphasizing methylene blue polychromes. A short biographical sketch of Giemsa is presented, as well as of the constitution and mechanism of action of his stain and unique HPLC analyses of his azur II (methylene blue $63.6 \%$, azur B 28.6\%, azur A 4.4\%, azur C 1,4\%, thionin 1.9\%): azur I was not "pure", it is a mixture of thionin and all of its 3 and $7 \mathrm{~N}$-methylated derivatives prepared most probably by acid oxidation as clarified by Lillie. Uses of Giemsa stain reported during the last 32 years are tabulated.

Key words: Giemsa, azure, methylene blue, polychrome methylene blue.

\section{Aclaración de los autores}

Biomédica

2003;23:5-18

\section{Cien años del colorante de Giemsa}

José Perea-Sasiaín

Laboratorio de Microscopía, Sección de Biología Celular, Departamento de Morfología, Facultad de Medicina, Universidad Nacional de Colombia, Bogotá, D.C., Colombia.

En las fórmulas esquemáticas de la figura 1 la unión del anillo heterocíclico central con el anillo bencénico izquierdo de los azures A, B Y C tiene una sola línea.

\section{Aclaración de los autores}

Biomédica

2003;23:263-73

\section{Identificación de antígenos de aislamientos colombianos de Giardia duodenalis reconocidos por Ig G total y subclases}

\author{
Jenny Fabiola Hernández ${ }^{1}$, Sofía Duque ${ }^{1,2}$, Adriana Arévalo ${ }^{1}$,
}

Rafael Guerrero ${ }^{3}$, Rubén Santiago Nicholls ${ }^{1,2}$

1 Laboratorio de Parasitología, Instituto Nacional de Salud, Bogotá, D.C., Colombia.

2 Unidad de Parasitología, Departamento de Salud Pública y Tropical, Facultad de Medicina, Universidad Nacional de Colombia, Bogotá, D.C., Colombia.

3 Gastroenterología Pediátrica, Universidad El Bosque, Bogotá, D.C., Colombia

Reproducido con autorización de la revista Médica Sánitas 2003;6(3):26-50. 